\title{
Participação cidadã na formulação da política pública do esporte catarinense
}

\author{
Clerilei ApARECIDA BIER \\ UniVERSIDADE do ESTAdo de SANTA CATARINA / CENTRO dE CIÊNCIAS DA AdMINISTRAÇÃO E SOCIOECONÔMICAS, \\ FLORIANÓPOLIS - SC, BRASIL
}

JoÃo PAULO BITTENCOURT

Universidade de SÃo PAulo / FACULdAde de ECONomia, AdMINISTRAÇÃo E CONTABILIDADE, SÃO PAULO - SP, BRASIL

Cauê Martins franco

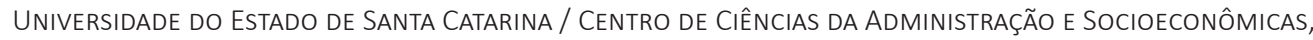
FLORIANÓPOLIS - SC, BRASIL

CLARISSA ISER

Universidade do Estado de SANTA CATARINA / Centro de CIÊNCIAS da AdMinistração e SOCIOeconômicas, FLORIANÓPOLIS - SC, BRASIL

\begin{abstract}
Resumo
No presente estudo investiga-se a participação cidadã no processo de elaboração da política pública do esporte catarinense, o que o caracteriza quanto ao seu objetivo como uma pesquisa descritiva. O período analisado inicia-se em 1992 e se estende até o ano de 2006 . O método utilizado foi o de estudo de caso, e a coleta de dados foi realizada por meio de diferentes técnicas pertinentes a este método, a saber: observação participante, entrevistas em profundidade e pesquisa documental. Os resultados demonstraram que, embora os principais atores sociais que participaram do processo de elaboração da política pública tenham sido principalmente aqueles que já estavam engajados anteriormente no processo da public policy making, a participação cidadã existiu sob a forma cooperativa e por meio de colegiados públicos.
\end{abstract}

Palavras-chave: Administração Pública. Políticas Públicas. Participação Cidadã.

\section{Citizen participation in public sports-related policy-making in Santa Catarina state}

\section{Abstract}

The present study investigates the process of citizen participation in public sports-related policy-making in the state of Santa Catarina, Brazil, and its purpose is therefore characterized as work of descriptive research. The analyzed period begins in 1992 and extends until the year 2006 and a case study method is used. Data collection was performed using different techniques relevant to the case study method, namely, participant observation, in-depth interviews and documentary research. The results showed that although the main social actors participating in the drafting of public policy had already previously been engaged in the process of public policy-making, some citizen participation did exist in a cooperative form and in the involvement of public collegiate bodies.

Keywords: Public Administration. Public Policy. Citizen Participation.

\section{La participación ciudadana en la formulación de la política pública del deporte catarinense}

\section{Resumen}

El presente estudio investiga la participación ciudadana en la elaboración de la política pública del deporte de la provincia de Santa Catarina, lo que le caracteriza cuanto a su objetivo como una investigación descriptiva. El período de la muestra comienza en 1992 y se extiende hasta 2006. El método utilizado fue el estudio de caso, y la recogida de datos se realizó a través de diferentes técnicas pertinentes a este método, a saber: la observación participante, entrevistas en profundidad y la investigación documental. Los resultados mostraron que aunque los principales actores sociales que participaron en la elaboración del proceso de políticas públicas eran principalmente aquellos que ya estaban comprometidos antes en el proceso de la public policy making, la participación ciudadana existía en forma cooperativa y por medio de las juntas públicas.

Palabras clave: Administración Pública. Políticas públicas. Participación ciudadana. 


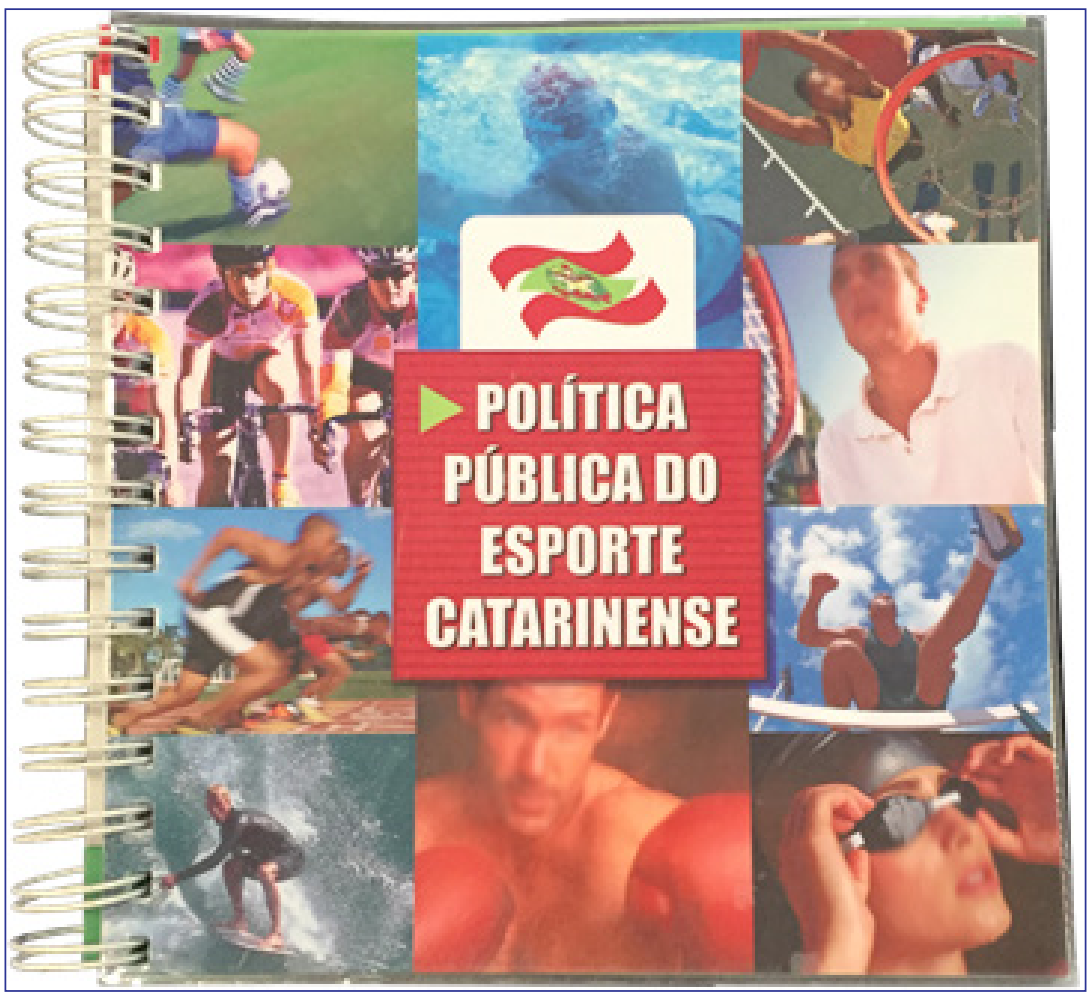

\section{INTRODUÇÃO}

Muito se tem falado da necessidade de uma maior participação dos cidadãos, seja individualmente ou por intermédio de associações e organizações da sociedade civil, tanto no controle e fiscalização das ações do Estado, como especialmente nos processos de criação e implementação de políticas públicas. Desse modo e dado o grau de complexidade que o tema participação cidadã envolve e os inúmeros questionamentos e poucas respostas trazidas ao debate, entende-se que o estudo e a análise de um caso concreto de processo de formulação de políticas públicas com participação cidadã, independente de ser considerada exitosa em sua plenitude, poderiam trazer importantes elementos para provocar a reflexão sobre o tema.

Neste diapasão, o presente artigo trata da participação no processo de formulação da política de esportes catarinense por parte de cidadãos, serviços sociais autônomos, entidades científicas, ligas, clubes e associações, ONGs, OSCIPS, empresas privadas e cooperativas - todos articulados pelo governo do estado de Santa Catarina por meio dos órgãos gestores do Sistema Catarinense de Desportos, em especial o Conselho Estadual de Desportos (CED) e a Fundação Catarinense de Esportes (FESPORTE).

Entender o processo de participação cidadã na elaboração de uma política pública torna-se relevante, dado que é com esta política que a administração pública busca prover os bens públicos aos cidadãos. Howlett e Ramesh (2003), após um levantamento bibliográfico consistente a respeito do assunto, verificaram que dificilmente o governo trata de um problema sozinho; as opiniões e decisões de outros setores são sempre levadas em conta, sendo possível a participação de diversos atores no public policy-making.

A participação cidadã é defendida por significar um maior envolvimento dos cidadãos com a finalidade de restringir os abusos de um sistema representativo (BARBER, 1984; BOX, 1998; PATEMAN, 1970). Além disso, para Roberts (2004), a participação

* Fonte da imagem: Banco de imagem dos autores. 
direta dos cidadãos nas decisões que influenciam suas vidas é educativa, serve para desalienação e protege a liberdade. A necessidade de compreender como ocorre a participação direta se dá em virtude de avaliar sua validade e possíveis limitações, separar o que é mito do que é realidade neste assunto e, com base nos resultados encontrados, indicar caminhos a serem trilhados no futuro (ROBERTS, 2004). Tendo em vista este contexto, o presente artigo tem por objetivo analisar a participação no processo que vem ocorrendo desde 1994 no estado de Santa Catarina para a formulação de uma política pública estadual de esportes.

Para atender este objetivo o artigo está estruturado de forma que na primeira seção se introduz o assunto. A segunda seção contém a fundamentação teórica, abordando-se os assuntos referentes ao Estado e à administração pública; políticas públicas e participação cidadã. A terceira seção contém um breve histórico da política pública do esporte em Santa Catarina. A quarta seção contém os aspectos metodológicos da pesquisa; a quinta seção, a discussão do caso; e a sexta seção, as considerações finais.

\section{PARTICIPAÇÃO CIDADÃ: PREMISSA SUBJACENTE NA ABORDAGEM ATUAL DE ESTADO, ADMINISTRAÇÃO PÚBLICA E POLÍTICAS PÚBLICAS}

\section{Estado e administração pública}

Apoiado na concepção weberiana de Estado moderno, Bobbio (1988) definiu Estado como um aparato administrativo com a função de prover a prestação de serviços públicos e possuidor do monopólio legítimo da força. Entretanto, têm-se observado mudanças significativas das funções e características deste Estado, sendo já possível identificar uma transição do Estado convencional para um novo modelo, no qual o conceito mais abrangente de governança pública emerge e, com ele, uma nova relação entre Estado e sociedade.

Nesta transição o Estado vem adquirindo, segundo Kissler e Heidemann (2006), as características de um Estado de serviço, produtor do bem público, para um Estado que serve de garantia à produção do bem público; de um Estado ativo, provedor solitário do bem público, para um Estado ativador, que aciona e coordena outros atores a produzir com ele; e de um Estado dirigente ou gestor para um Estado cooperativo, que produz o bem público em conjunto com outros atores. Características, nesse caso, mais adequadas para o enfrentamento dos problemas das sociedades contemporâneas.

No Brasil o modelo atual de Estado e sua administração burocratizada e ineficaz têm resultado em dificuldade no enfrentamento dos principais problemas que afetam a nossa sociedade. Isso leva à necessidade de redefinição de estratégias de articulação das políticas públicas, à instauração de diversos programas reformistas e ao surgimento de novos modelos de administração pública, em que há prioridade do fortalecimento de uma cidadania ativa, na qual o cidadão, portador de direitos e deveres, é essencialmente criador de direitos para abrir novos espaços de participação política. Por sua vez, a administração pública deve incentivar e coordenar tais processos a fim de fortalecer a democracia.

Um dos mais recentes modelos de administração pública voltado a estas prioridades é o Novo Serviço Público, de Denhardt e Denhardt (2003). O modelo do New Public Service origina-se da tradição humanista democrática da administração pública e aborda pontos como cidadania e comunidade. Este modelo normativo é uma proposta alternativa à ideia de escolha racional e provém de teorias e práticas mais humanísticas da teoria da administração já utilizadas por diversos administradores públicos mundo afora (DENHARDT e DENHARDT, 2003).

As principais características do Novo Serviço Público, segundo Denhardt e Denhardt (2003), são:

- $\quad$ servir cidadãos e, não, consumidores;

- busca pelo interesse público;

- valorizar a cidadania acima do empreendedorismo;

- pensar estrategicamente, agir democraticamente;

- reconhecer que accountability não é simples; 
- $\quad$ servir em vez de dirigir;

- valorizar as pessoas, não somente a produtividade.

O cidadão, neste novo modelo de administração pública, deixa de ser um mero receptor de benefícios para se tornar um agente de mudança, e o Estado deixa de ser o grande provedor de benesses para ser o incentivador e facilitador de processos democráticos. Com isso, o cidadão colabora com a geração de benefícios para si e para sua comunidade.

Neste novo modelo de administração pública, o cidadão deve ser mais ativo e engajado, e socialmente responsável, assim como o Estado deve ser mais transparente e acessível, articulador. A cidadania ativa se mostra como a questão chave deste novo discurso, e seu ponto de partida está na mudança de valores da sociedade, de modo que o cidadão participa diretamente e sobrepõe a seu interesse particular aquilo que é de interesse público.

Esta busca do interesse público, com preponderância do interesse da maioria e potencialização dos interesses comunitários frente aos interesses individuais defendidos na teoria do Novo Serviço Público, é destacada por Denhardt em sua afirmação de que:

Para nós, cidadãos, é importante reconhecer que tornar nosso país e nossas comunidades melhores requer no mínimo nossa cooperação, e idealmente, nosso envolvimento ativo. Por definição, nosso governo nos pertence e é de nossa responsabilidade. Nós podemos e deveríamos ter altas expectativas do governo; mas para o governo funcionar bem, é preciso cidadania ativa. (DENHARDT e DENHARDT, 2003, p. 175).

Neste diapasão, um dos grandes desafios nas reformas administrativas é a busca por uma administração pública sólida com um papel maior e mais democrático designado à proteção do bem público e do bem-estar dos cidadãos, e que traga para o palco central da administração pública uma face humana, na qual as pessoas estão em primeiro lugar. Tem-se, assim, um Estado ativo, que encoraja a participação (democracia participativa) e utiliza recursos estatais para promover a justiça social revitalizando a sociedade civil e comprometendo-se com o cidadão (SALOOJEE e FRASER-MOLEKETI, 2010; NEF, 2010).

\section{POLÍTICAS PÚBLICAS}

A ação da administração pública na provisão dos bens públicos se dá, principalmente, durante a elaboração de políticas públicas que têm como objetivo a resolução de questões políticas, sociais e econômicas da sociedade. Mas entender o conceito e o processo de elaboração de uma política pública não é uma tarefa simples.

Em termos de definição, são muitas as existentes. De acordo com a Enciclopédia de Administração Pública (2008), uma das primeiras definições de que se tem notícia foi apresentada por Harold Lasswell ainda em 1936: política pública é a decisão de um governo de quem fica com o que, quando e como. Thomas Dye, por sua vez, apontou que política pública é tudo aquilo que o governo escolhe fazer ou deixar de fazer (DYE, 2002). Ambas as definições são bastante amplas e nos ajudam a compreender que toda política pública depende de um governo para ocorrer. Entretanto, existem outros detalhes importantes que não estão presentes nestas definições.

No intuito de esclarecer melhor este assunto, Howlett e Ramesh (2003) acrescentam outras definições para política pública. Uma delas é a de William Jenkins:

[...] um conjunto de decisões inter-relacionadas, tomadas por um ator ou grupo de atores políticos, que se refere à seleção de objetivos e dos meios necessários para lográ-los, numa situação especificada em que o alvo dessas decisões estaria, em princípio, ao alcance efetivo desses atores (JENKINS, 1978, apud HOWLETT e RAMESH, 2003, p. 11).

Nesta definição, muito mais detalhada, observamos a compreensão da política pública como um processo dotado de meios para atingir determinados fins. $E$, ainda, que muitas decisões são tomadas tendo em vista a capacidade do governo de atingir tal objetivo, ou seja, que as ferramentas de que o governo dispõe são um fator limitante e trazem impactos à sua decisão. Podemos notar também que Jenkins, ao mencionar que política pública trata de decisões inter-relacionadas, admite que, além do governo, outros atores participam do processo. Desse modo, apesar de concordarem que quase sempre quem executa 
a política pública é o governo, Howlett e Ramesh (2003) consideram que dificilmente o governo trata de um problema sozinho, isto é, as opiniões e decisões de outros setores são sempre levadas em conta no processo da política pública. Atores sociais interagem e se relacionam por meio do que Howlett e Ramesh chamaram de universo da política pública (Figura 1).

Figura 1

\section{Universo da Política Pública}

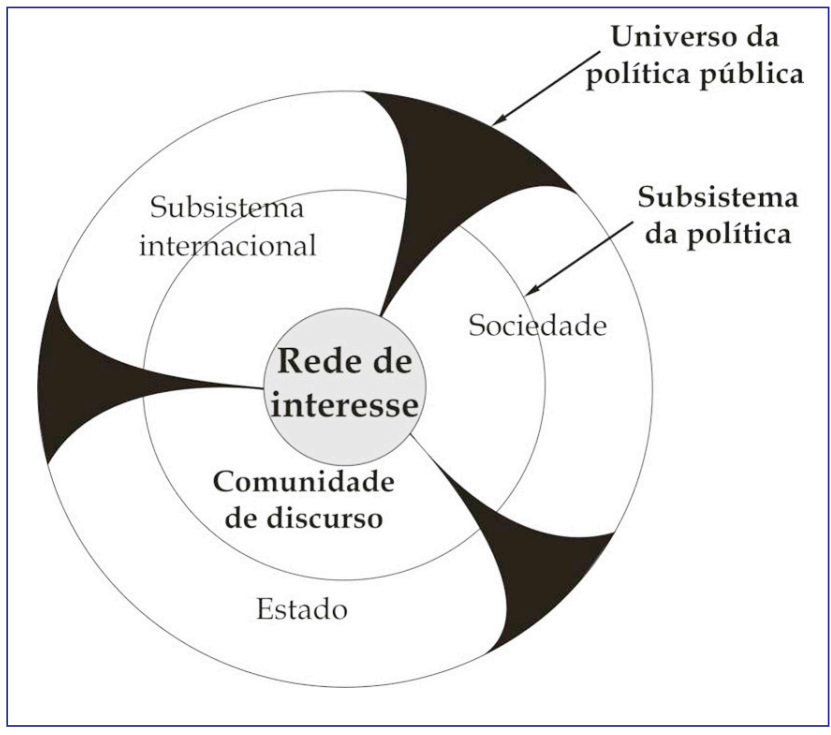

Fonte: Howlett e Ramesh (2003).

O universo da política é a unidade fundamental na qual estão inseridos todos os atores e instituições relevantes, sejam internacionais, estatais e sociais, que, direta ou indiretamente, afetam uma política pública específica. O universo é composto de subsistemas de política pública, espaços em que os atores relevantes discutem as questões políticas, exercem persuasão e fazem barganhas em favor de seus interesses. O subsistema político inclui tanto os atores sociais profundamente engajados em um processo político - as redes de interesse -, quanto aqueles apenas perifericamente envolvidos - as comunidades do discurso. Apesar de se tratar de um universo amplo, a política pública sempre ocorre num espaço circunscrito, seja em uma sociedade ou Estado. É neste espaço, ou subsistema político, que o processo de política pública opera, contando sempre não apenas com o envolvimento do governo, mas também com o de outros atores sociais relevantes situados nas redes de interesse e nas comunidades de discurso.

Apesar de ser um processo extremamente complexo e truncado, esforços foram feitos no sentido de desmembrá-lo de políticas públicas. A ideia de simplificar a complexidade da public policy-making já havia sido mencionada pela primeira vez nos trabalhos iniciais de Harold Lasswell. Por isso, e com o intuito de compreender melhor o modus operandi de uma política, Howlett e Ramesh (2003) desdobraram o processo em uma série de estágios distintos, porém, interdependentes. Como resultado desta simplificação, temos uma sequência de cinco estágios: a montagem da agenda; a formulação da política; a tomada de decisão; a implementação e a avaliação. Juntos, estes estágios compreendem o ciclo ou processo da política pública.

Nesse ciclo, a montagem da agenda refere-se a como os problemas públicos chegam à atenção dos governos; a formulação da política, à forma pela qual as opções de políticas são formuladas dentro do governo; a tomada de decisão, à forma pela qual os governos adotam um curso particular de ação ou de não ação; a implementação de uma política trata de como os governos efetivamente põem as políticas em prática; e a avaliação da política refere-se aos processos pelos quais tanto os atores do Estado como os da sociedade monitoram os resultados das políticas, podendo decorrer daí uma redefinição dos problemas e das soluções político-administrativas propostas nos estágios anteriores.

A ideia de simplificar a complexidade da public policy-making em um ciclo possui algumas vantagens: trata-se de uma ferramenta analítica que facilita o entendimento da public policy-making; pode ser usada em todas as esferas de governo; permite 
examinar o papel de todos os atores e instituições envolvidos na criação de políticas. A principal desvantagem está na possível interpretação de que os policy-makers resolvem problemas públicos de uma maneira sistemática e linear. Ocorre que, em realidade, a identificação de problemas e o desenvolvimento e implementação de soluções são muitas vezes processos bastante idiossincráticos e determinados pelo contexto social e político. Ou seja, os tomadores de decisão geralmente apenas reagem a circunstâncias de acordo com os seus interesses e ideologia (HOWLETT e RAMESH, 2003).

Tais definições, conceitos, estágios e ciclos ajudam a compreender que política pública é uma ação governamental, ou seja, é uma ação que determinado grupo que está no comando do aparato estatal toma tendo em vista uma série de questões presentes nos contextos histórico, econômico e social vigentes. Tal contexto permite compreender por que determinado problema social tomou corpo e se tornou alvo de uma política pública e de que forma esta foi implementada e, posteriormente, avaliada. A participação de demais atores sociais, além daquela do Estado, vai sempre ocorrer. No entanto, vai variar de acordo com a posição destes no momento em que a política pública está sendo feita. A presença, análise e interpretação destas questões de contexto e de participação revelam por que o Estado fez o que fez e, assim, é possível avaliar as consequências de suas ações (em forma de políticas públicas) na sociedade.

\section{PARTICIPAÇÃO CIDADÃ}

Entre os dilemas, oportunidades e desafios da administração pública contemporânea, a questão que mais se destaca - além da que se refere à restrição de recursos e competências do Estado na provisão do bem público - é a da fragilidade da democracia representativa e seu resultado: não propiciar aos cidadãos a participação direta nas decisões que influenciam suas vidas. Nesse âmbito, inúmeros são os questionamentos e poucas as respostas concretas, dado o grau de complexidade que tais assuntos implicam.

Por essa razão, Roberts (2004) enfatiza que é necessário aprofundar o estudo sistemático da participação direta de cidadãos nas decisões da administração pública, a fim de compreender sob quais circunstâncias esta participação é satisfatória ou bem-sucedida e sob quais redundou em fracasso.

A participação pode ocorrer por meio de mecanismos ligados diretamente ao Estado ou de forma autônoma em relação a este. O Estado em crise não consegue dar resposta às demandas da sociedade, sobretudo dos segmentos mais empobrecidos, o que conduz ao surgimento de movimentos sociais. Estes constituem-se como atores sociais e políticos, construindo sua identidade e autonomia como nova maneira de encarar o Estado e de agir coletivamente para expressar suas aspirações e necessidades (TEIXEIRA, 1997).

Dessa maneira, da perspectiva da participação, os diversos interesses da sociedade civil, que é fragmentada e heterogênea, articulam-se em espaços públicos, são temas das questões de interesse geral, concertam proposições e parâmetros negociados com os representantes do Estado. Mantém-se a autonomia da sociedade civil, que também se autolimita no sentido de que não busca substituir o Estado, ou o mercado, mas exercer controle e o permanente questionamento sobre atos, políticas e decisões.

A participação em políticas públicas pressupõe o uso de mecanismos institucionais e sociais, disponíveis ou a serem criados, incluindo-se, aí, os de representação que precisam ser reformulados e aperfeiçoados. Nesse caso, busca a efetivação dos direitos já consagrados, mas, vai além, tenta construir novos direitos, fortalecendo a sociedade civil no exercício de seu papel político (MODESTO, 2002).

Dentre os objetivos da democracia participativa - além do relativo ao resgate da dimensão pública e cidadã na política por meio da mobilização de setores sociais interessados na realização de políticas públicas -, estabelece-se uma nova relação entre cidadania e política, uma gestão social que por intermédio dos movimentos sociais atua pela ampliação do político, pela transformação de práticas dominantes, pelo aumento da cidadania e pela inserção na política de atores sociais excluídos (ressignificação das práticas democráticas). Possibilita-se a sobreposição de uma subjetividade emergente, capaz de explorar as possibilidades emancipatórias e alternativas sociais assentadas na transformação das relações de poder em relações de autoridade partilhada, e transformação das ordens jurídicas despóticas em ordens jurídicas democráticas. 
Sem embargo, não basta agir para o social, mas, com o social, conforme Tenório e Saravia. Gestão pública é o fim e gestão social, o meio.

A qualificação gestão social agregaria valores democráticos à gestão pública, na medida em que esta deveria atuar considerando que o seu processo de tomada de decisão deve ser executado levando em conta a soberania popular, ou seja, por meio de ações concertadas com a cidadania de modo dialógico. A gestão social não deve, portanto, ser apenas a prática de uma gestão pública voltada para a solução de problemas sociais como muitos idealizam, mas uma prática gerencial que incorpore a participação da sociedade no processo de planejamento e implementação de políticas públicas. (TENORIO e SARAVIA, 2006, p. 129).

No Brasil, conforme assinala Albuquerque (2004), existe uma tendência de se entenderem como práticas participativas aquelas que envolvem a cogestão entre Estado e sociedade. A autora destaca três experiências desse tipo: os orçamentos participativos, os conselhos gestores e as relações de 'parceria' entre Estado e sociedade.

Além dessas, é preciso apontar outras formas de participação, que não se voltam para a cogestão e cuja incidência sobre as políticas públicas, embora muito relevante, não se dá por meio de canais institucionalizados. Dentre elas, destacam-se o MST (Movimento dos Sem Terra), a Pastoral da Criança, os fóruns de iniciativa civil, como, por exemplo, o Fórum Nacional da Reforma Urbana ou a Ação da Cidadania (ALBUQUERQUE, 2004). E, também, as novas formas de manifestação cidadã, muito mais informais, como as redes de 'militância virtual', as consultas e pesquisas realizadas por telefone, questionários ou internet, os movimentos de consumidores e usuários. A participação meramente formal propiciada pelas 'tecnologias da comunicação' pode ser integrada a outras formas de participação a fim de torná-la mais substantiva.

Sousa Santos e Avritzer (2003) ressaltam as potencialidades da participação, analisando casos brasileiros e indianos nos quais as práticas de participação surgem de mudanças em práticas societárias introduzidas pelos próprios atores sociais; além disso, resgatam tradições democráticas locais a princípio ignoradas pelas formas de democracia representativa hegemônicas nestes países. Com isso, Sousa Santos (2006) ressalta a necessidade de uma 'reinvenção' do Estado ou do que ele chamou de Estado-novíssimo-movimento-social.

O Estado-novíssimo-movimento-social caracteriza-se por uma articulação privilegiada entre os princípios do Estado e da comunidade e pode ajudar a vencer os desafios que se impõem à participação. Não significa um Estado fraco ou ausente, mas sim um ente megarregulador: selecionando, coordenando, hierarquizando e regulando os demais agentes não estatais presentes na sociedade civil. Com isso, a luta política ocorre em um espaço público muito mais amplo que o público estatal. Neste novo espaço público, agora mais amplo, a administração pública é uma caixa de ressonância na qual os problemas encontrados na sociedade civil tomam corpo (HABERMAS, 2003). Suas instituições seriam encarregadas de assegurar o funcionamento efetivo da esfera da opinião pública, donde as questões práticas de interesse geral seriam submetidas à discussão pública e se decidiria sobre a base de um acordo alcançado discursivamente. São fluxos de comunicação da sociedade civil, que surgem da esfera da vida privada (mundo da vida) e são impulsionadas num espaço público ativo (MCCARTHY, 2013).

Operacionalizar a ampla participação, entretanto, possui desafios também quanto à forma como irá ocorrer e quanto aos instrumentos a serem utilizados para propiciá-la. Enterria e Fernández (1998) elaboraram as possíveis classificações de formas de participação na administração pública:

a) participação orgânica: inserção dos cidadãos, nesta qualidade (não como funcionários ou políticos), em órgãos públicos (ex.: corporações públicas; administração não corporativa; ou também por meio do uso de técnicas de representação de interesses e técnica de colaboração de especialistas);

b) participação funcional: atuação cidadã fora do aparato administrativo, mas em atividades materialmente públicas, com o auxílio ou concordância da administração (ex.: consultas públicas; denúncias; exercício de ações populares; petições e propostas);

c) participação cooperativa: atuação do cidadão como sujeito privado, sem exercer função materialmente pública, mas em atividades de interesse geral, com apoio do poder público (ex.: atividades de entidades de utilidade pública, entre outras). 
Para que as formas de participação classificadas por Enterria e Fernández (1998) sejam possíveis, Modesto (2002) lembra que é necessária a existência de instrumentos processuais que as propiciem. Segundo o autor, há vários desses instrumentos hoje empregados na administração pública, com maior ou menor grau de autenticidade e integração social. Nos limites desta intervenção, cabe referir, em especial, os seguintes, quando empregados para tutela de interesses sociais:

a) consulta pública (abertura para manifestação por escrito de terceiros, antes de decisão, em matéria de interesse geral);

b) audiência pública (sessão aberta ao público, sobre tema ainda passível de decisão);

c) colegiados públicos (reconhecimento a cidadãos ou a entidades do direito de integrar órgão de consulta ou de deliberação colegial no poder público);

d) assessoria externa (convocação da colaboração de especialistas para formulação de projetos, relatórios ou diagnósticos sobre questões a serem decididas);

e) denúncia pública (instrumento de denúncias quanto ao mau funcionamento ou responsabilidade especial de agente público; ex.: representação administrativa);

f) reclamação relativa ao funcionamento dos serviços públicos (fundamenta-se em relação jurídica entre o Estado ou concessionário do Estado e o particular-usuário);

g) colaboração executiva (organizações que desenvolvam, sem fim lucrativo, com alcance amplo ou comunitário, atividades em áreas de atendimento social direto);

h) ombudsman (ouvidor);

i) participação ou 'controle social' mediante ações judiciais (ação ou civil pública, mandado de segurança, ação de inconstitucionalidade de lei ou ato normativo, entre outras);

j) fiscalização orgânica (obrigatoriedade, por exemplo, de participação de entidades representativas em bancas de concursos públicos; por exemplo, $\mathrm{OAB}$ ).

Vários desses mecanismos procedimentais encontram fundamento constitucional direto (CF, v.g. art. 5, XXXIII, XXXXIV, "a",

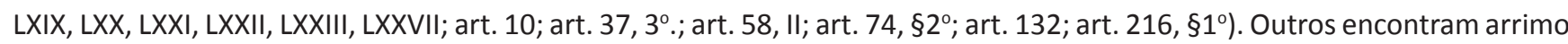
em regulação infraconstitucional, como os constantes da Lei de Normas Gerais de Processo Administrativo (Lei 9784/99, v.g. art. 31 a 34). Mas, indistintamente, esses instrumentos são pouco utilizados e conhecidos, a demonstrar que a questão é, sobretudo, cultural, vinculada a nosso passado colonial e a nossas práticas de exploração das vantagens produzidas pela coletividade, antes de ser um problema de lacuna normativa (MODESTO, 2002).

Portanto são instrumentos que podem servir à participação popular, à expressão política da coletividade, mesmo quando desencadeados por indivíduos singulares. No entanto, nem sempre receberam esse matiz, caracterizando-se, em alguns casos, como meros instrumentos de participação pessoal, homenageando interesses exclusivamente privados. Quanto a isso, assinala Britto (1992) que a participação popular somente ocorrerá quando for possível identificá-la como manifestação de poder político e não como simples expressão de direito público subjetivo.

\section{BREVE HISTÓRICO DA POLÍTICA PÚBLICA DO ESPORTE EM SANTA CATARINA}

A maioria das informações constantes neste item foi elaborada com base nos resultados das pesquisas realizadas para este estudo. Desta forma, contribuíram para a elaboração do texto que segue abaixo a observação participante e, em especial, a pesquisa documental e as entrevistas em profundidade.

O Estado brasileiro sempre relegou ao esporte uma posição secundária frente a outras questões, como, por exemplo, saúde e educação (SUASSUNA, 2007). No âmbito federal é somente no governo de Getúlio Vargas, a partir de 1937, que algumas ações são tomadas a fim de impulsionar o esporte no país. O então presidente cria, entre os anos 1930 e 1940, a Divisão de Educação Física, vinculada ao Ministério da Educação e Saúde, a Escola de Educação Física da Universidade do Brasil (atual UFRJ) e o Conselho Nacional de Desportos (CND). Durante o regime militar a política pública teve aspectos interessantes como o reconhecimento dos atletas, da sua seguridade física e social. Mas também revelou outros aspectos, como a grande 
presença do Estado na questão do esporte. A Lei 6.354 deu plenos poderes ao Estado, que passou a regular a relação entre clubes e atletas (até mesmo quando o assunto era passe) - diversas intervenções puderam ser observadas na época.

Com o advento da Constituição Federal de 1988, ficou clara a preocupação com o esporte por parte dos legisladores, cabendo ao Estado novas funções como, por exemplo, fomentar as práticas esportivas, garantir a autonomia de associações esportivas e investir no desporto educacional e também no de alto rendimento. Destacam-se, a partir disso, a criação da Lei 8.672, de 1993, chamada de Lei Zico; a criação do Ministério Extraordinário do Esporte em 1995; e a criação, em 1998, da Lei 9.615, conhecida como Lei Pelé (ALVES e PIERANTI, 2007).

Após a Constituição Federal de 1988, a Assembleia Legislativa do estado de Santa Catarina, na elaboração da última Constituição Estadual no ano de 1989, preceituou ao Estado a missão de fomentar práticas desportivas formais e não formais. No desdobramento desta incumbência, três importantes passos foram dados objetivando equipar o desporto catarinense com uma estrutura básica fundamental ao cumprimento daqueles dispositivos constitucionais.

Primeiramente é criado o Conselho Estadual de Desportos (CED) pela Lei 8.646, de 04 de junho de 1992. Em seguida, elabora-se o Código de Justiça Desportiva, o qual dá origem ao Tribunal de Justiça Desportiva (TJD), e, finalmente, a Lei 9.131, de 06 de julho de 1993, dá origem à Fundação Catarinense de Desportos (FESPORTE), atual órgão público de gestão do esporte catarinense, ligado à SOL (Secretaria de Estado da Cultura, Turismo e Esporte).

Antes da criação do CED, a organização do esporte no estado era coordenada pelo então chamado Conselho de Representantes - uma espécie de conselho de notáveis que representava o estado nas suas diversas regiões. Estes representantes auxiliavam na organização do principal evento esportivo do estado, os Jogos Abertos de Santa Catarina (JASC), além de outros eventos esportivos nos municípios e regiões (VAZ, 2001).

Com o advento do CED, foi possível criar a FESPORTE e o TJD, acontecimentos que contribuíram para a participação da sociedade na questão do esporte. No passado, os membros que formavam o Conselho de Representantes eram todos indicados pelo governo do estado que, por sua vez, adotava um critério político-esportivo para realizar a escolha. Com a criação do CED, uma parte significativa dos membros deste conselho passou a ser indicada pelos representantes dos municípios e das regiões do estado. Além disso, as associações esportivas, como foi o caso da Associação das Federações Desportivas em 1995, também passaram a indicar seus representantes para compor o conselho do CED.

Após este primeiro momento de estruturação do aparato estatal para atender as demandas esportivas da sociedade, foram realizadas, a partir do ano de 1994, uma série de debates em busca de diretrizes para o desenvolvimento da atividade esportiva estadual. Este processo teve como principal objetivo organizar a participação de diversos setores do esporte na elaboração de um documento de estado. Como resultado deste processo, é criada a Lei 9.808/94, que institui o Sistema Catarinense de Desporto e, posteriormente, é formatado o primeiro esboço de um Documento de Política Pública do estado de Santa Catarina.

A estrutura do recém-criado Sistema Catarinense de Desporto era constituída por gestores e trabalhadores - enumerados a seguir.

\section{Os gestores:}

1) Secretaria de Estado da Cultura, Turismo e Esporte (SOL);

2) Fundação Catarinense de Desportos (FESPORTE);

3) Conselho Estadual de Desportos (CED);

4) Tribunal de Justiça Desportiva (TJD);

5) entidades e órgãos estaduais de administração do desporto;

6) federações desportivas, ligas esportivas ou equivalentes e seus filiados;

7) entidades e órgãos municipais de administração (FMEs, CMEs) e de prática do desporto (clubes);

8) Secretaria de Estado da Educação, Tecnologia e Inovação (SEC);

9) Instituições de Ensino Superior (IES);

10) serviços sociais autônomos, entidades científicas, ligas, clubes e associações, ONGs, OSCIPS, OSs, empresas privadas, cooperativas e consórcios públicos em atuação como promotores da prática esportiva e de lazer. 


\section{Os trabalhadores:}

1) profissionais da área de esporte e lazer, suas respectivas entidades de representação (associações profissionais, sindicatos e federações) e conselhos profissionais das profissões regulamentadas;

2) usuários (representados por todo e qualquer membro da sociedade): atletas, estudantes, idosos, crianças, jovens, adultos, pessoas com deficiência e pessoas com necessidades especiais, conselhos de direito (idosos, pessoas com deficiência, pessoas com necessidades especiais e outros) e suas respectivas entidades de representação (entidades estudantis, sindicatos, ONGs, associações de moradores, sociedades agrícolas, associações agroextrativistas, assentados da reforma agrária, associações de jovens, povos indígenas e quilombolas).

Com a estruturação do Sistema Catarinense de Desportos foi possível organizar, no ano de 1997 em Florianópolis, o Primeiro Fórum Catarinense de Desportos. Estiveram presentes aproximadamente 400 pessoas. A convocação para participação neste fórum foi realizada por meio da figura dos mobilizadores regionais ligados ao CED. Com isso, a maioria dos presentes - a base das pessoas participantes do I Fórum - era formada por pessoas ligadas, de alguma forma, às prefeituras municipais do estado, contatadas pelos mobilizadores regionais do CED.

No ano seguinte, 1998, as entidades participantes do I Fórum, ainda em sua maioria ligada ao Sistema Catarinense de Desportos, participaram do Comitê de Revisão da Política Estadual de Desportos. Este Comitê tinha como objetivo revisar o primeiro esboço do Documento de Política Pública do Estado de Santa Catarina inicialmente formatado em 1994, com os subsídios e as informações levantados no I Fórum. O comitê obteve sucesso e o resultado foi a elaboração de uma prévia de um documento de política pública do estado. Como conclusão deste processo, foi apresentado o Plano de Ação para o biênio 2000/2001, cuja primeira ação seria a descentralização das discussões em fóruns regionais. A partir daí, estrutura-se o Segundo Fórum Catarinense de Desportos no biênio de 2000/2001, tendo como principais temas um plano de metas e ações diversas.

No ano de 2002 é realizado o Terceiro Fórum Catarinense de Desportos. O principal objetivo era avaliar o espaço percorrido com base nas propostas do que fora idealizado em 2000 para o ano de 2010, apresentando as conquistas feitas até aquele momento, a realidade concreta das metas que se transformaram em ações e a distância entre o que foi concebido e o possível de ser feito. Já no quarto e último Fórum Catarinense de Desportos, no ano de 2003, os principais temas tratados foram: esporte escolar, rendimento e propostas de redação livre.

A realização destes fóruns no período de 1998 a 2003 evidenciou uma preocupação por parte do estado em envolver os diversos atores do setor na discussão e elaboração de uma política pública estadual de esportes. Desta forma, o estado optou por envolver a população ligada ao esporte desde a definição das principais questões, até a elaboração de planos de ação para cada uma destas questões.

Assim como ocorreu no primeiro, estiveram presentes nos demais fóruns os representantes das instituições do Sistema Catarinense de Desportos, como o CED, a FESPORTE, o TJD e a SOL, além de pessoas ligadas ao esporte das prefeituras municipais. Estiveram presentes, ainda, diretores de escolas, conselhos regionais, diretores de clubes, imprensa (rádio) e líderes e representantes do esporte dos municípios e regiões. Entretanto, não houve investimentos ou esforços em comunicação de massa (aberta) para chamar a população a participar destes fóruns. Líderes comunitários e ONGs passaram a estar mais presentes nestas discussões somente a partir do IV Fórum (2003). Mas, apesar das limitações, este processo de discussão e elaboração de uma política pública estadual de esportes 'credenciou' o estado a participar da Primeira Conferência Nacional de Esportes.

A Primeira Conferência Nacional de esportes em 2004 reuniu, em Brasília, 1.200 delegados, escolhidos em assembleias estaduais e municipais em todo o país. Estes delegados discutiram os objetivos, diretrizes e bases de uma política nacional de esporte.

Em Santa Catarina, a escolha dos delegados deu-se da seguinte forma: inicialmente foram feitas reuniões públicas no município sede de cada região do estado. Durante estas reuniões em plenário, cerca de 150 participantes (pessoas ligadas ao esporte na região) nomeavam entre 10 a 15 delegados que os representariam em nível estadual. Este processo ocorreu em todas as regiões do estado, gerando um total de aproximadamente 300 delegados. 0 governo do estado custeou a ida de todos estes à cidade de Balneário Camboriú, onde houve novamente um processo de escolha: apenas 30 dos 300 delegados iriam representar o estado em Brasília, na I Conferência Nacional de Esportes.

Tal escolha se deu por meio da formação de chapas, entretanto, durante o processo evitou-se o confronto, acordos foram feitos e as escolhas foram negociadas, e, com isso, chegou-se a um consenso. Este modelo foi adotado tendo por finalidade 
permitir que cada região pudesse escolher o delegado que iria representá-la. As lideranças regionais e municipais (mobilizadores regionais do CED em sua maioria) fizeram a diferença neste processo. Apesar de estes atores subordinarem-se à FESPORTE e, portanto, representarem o estado, a sua atuação se deu principalmente nas regiões e nos municípios. Isso garantiu que a escolha dos delegados fosse feita com a participação dos atores sociais locais ou regionais. Além disso, todo este processo foi aberto ao público, com eventos gratuitos, possibilitando a participação popular. Mediante solicitação, qualquer pessoa poderia participar. Mas, assim como nos fóruns, não houve ampla divulgação para chamar mais pessoas ao processo.

Em 2004, após a Primeira Conferência Nacional de Esportes em Brasília, dá-se início ao processo de estruturação da participação do estado de Santa Catarina para a próxima conferência no ano de 2006. Foram os mesmos caminhos trilhados em 2004 para organizar a participação da sociedade. Para tanto, o estado organizou conferências regionais durante o mês de março de 2006 nas cidades de São Miguel do Oeste e Chapecó, Joaçaba e Concórdia, Lages e Caçador, Blumenau e Rio do Sul, Joinville e Itajaí e Criciúma e Florianópolis. Após o término das etapas regionais, o estado deveria realizar a etapa estadual onde seriam eleitos os delegados. Com isso, foi realizada a Conferência Estadual em Balneário Camboriú nos dias 30 e 31 de março, sendo definidos, de forma similar à que ocorreu em 2004, os delegados que participaram da II Conferência Nacional em 2006.

Sem embargo, a iniciativa associativista, existente em SC, de articulação territorial pelo desenvolvimento, viu-se prejudicada em face da criação, em 2003, das Secretarias de Desenvolvimento Regional (SDR), conforme explicam Filippim e Abrucio (2010) ao analisar a experiência de descentralização pela via do governo estadual em Santa Catarina, iniciada em naquele ano. As SDRs assumiram parte das funções das secretarias centrais/setoriais e foram incumbidas de promover o desenvolvimento de suas regiões.

Este movimento do governo do estado apresenta, conforme Filippim e Abrucio (2010), um conflito entre dois modelos descentralizadores: o nascido nos municípios e redes locais de articulação da sociedade civil e o originado do governador Luiz Henrique, articulado em nome da regionalização e da aproximação do governo estadual com os cidadãos. Ao não respeitar a atuação dos antigos fóruns de desenvolvimento e/ou das associações de municípios, por meio da rede de cooperação municipalista presente no estado, a criação das SDRs implicou em um retrocesso no movimento de participação cidadã na política pública do esporte do estado (FILIPPIM e ABRUCIO, 2010). Por esta razão o período selecionado no presente estudo está centrado nos anos de 1998 a 2003.

\section{METODOLOGIA}

Esta seção apresenta os aspectos referentes às características da pesquisa, a abordagem, o método e as técnicas utilizadas. Por investigar a participação cidadã no processo de elaboração da política pública do esporte catarinense, o presente estudo caracteriza-se quanto aos seus objetivos como pesquisa descritiva (DENCKER, 2000; GIL, 1999). Adotou-se a abordagem qualitativa, a qual geralmente oferece descrições ricas e bem fundamentadas, além de explicações sobre processos em contexto e locais identificáveis (VIEIRA, 2004). O método escolhido foi o estudo de caso, por permitir analisar em profundidade uma determinada situação. Para Dencker (2000), o objeto do estudo de caso pode ser um indivíduo, um grupo, uma organização, um conjunto de organizações ou, até mesmo, uma situação. Adotou-se aqui o estudo de caso muito menos por seu caráter exaustivo e mais por possibilitar a interação direta entre contexto e fenômeno, cujos limites são bastante tênues (YIN, 2001).

A coleta de dados foi realizada por intermédio de diferentes técnicas, conforme prevê Gil (1999) a respeito dos instrumentos de coleta adequados ao estudo de caso. A primeira técnica utilizada para coletar os dados foi a observação participante, realizada de forma assistemática por parte de uma das pesquisadoras, que atuou como consultora em diferentes etapas do processo, como a elaboração do documento de orientação da política e a organização da participação do estado nas conferências nacionais de esportes (UNESPORTE, 2009). Esta técnica contribuiu para a compreensão dos seguintes itens: o processo de organização da participação do estado nas conferências nacionais; a organização e dinâmica interna dos fóruns catarinenses; e o processo de construção do documento de política pública do esporte de Santa Catarina. Além disso, a presença desta pesquisadora como consultora no processo facilitou o acesso dos demais pesquisadores aos documentos oficiais bem como aos entrevistados. 
Com o intento de levantar informações a respeito da participação cidadã na elaboração da política, fez-se uso de uma segunda técnica, a de entrevistas em profundidade. Para a escolha das pessoas que seriam entrevistadas foram adotados os seguintes critérios: 1) ocupar ou ter ocupado cargo em algum dos órgãos gestores do Sistema Catarinense de Desportos entre 1992 e 2006; 2) ter participado diretamente em, no mínimo, algum destes processos: (a) elaboração do documento de política pública do estado, (b) organização dos fóruns catarinenses de desportos e das conferências nacionais; 3) possuir histórico de envolvimento com o esporte no estado de Santa Catarina. Após a aplicação destes critérios, foram entrevistados cinco atores que atendiam à especificação. As entrevistas ocorreram entres os dias 03 de junho a 10 de julho de 2009 e duraram, em média, 2,5 horas.

Durante as entrevistas, foi utilizado um roteiro padronizado. Segundo Goldenberg (1999), a entrevista padronizada com perguntas abertas consiste em apresentar as perguntas da mesma maneira e na mesma ordem a todos os entrevistados. Nesta técnica, as respostas dos entrevistados são livres na medida em que não são limitadas por alternativas de resposta apresentada pelo entrevistador, seguem apenas um roteiro de entrevista com perguntas previamente elaboradas. Esta técnica é amplamente utilizada em pesquisas de ciências sociais para a coleta de dados e informações em profundidade. Durante as entrevistas, de acordo com o roteiro, os entrevistados eram solicitados a responder perguntas sobre: 1) seu histórico profissional e pessoal com o esporte no estado; 2) o surgimento do Sistema Catarinense de Desporto e seus órgãos gestores; 3 ) o surgimento do primeiro Documento de Política Estadual do Esporte; 4) antecedentes e detalhes sobre o processo de organização dos Fóruns Catarinenses e das Conferências Nacionais, em especial detalhes sobre a participação dos demais atores sociais nestes processos; 5) evidências (convites, memorandos, listas de presença etc.) dos Fóruns e das Conferências e como encontrá-las; 6) outras informações relevantes que poderiam ajudar os pesquisadores a compreenderem a participação cidadã que vem ocorrendo desde 1994 no estado de Santa Catarina para a formulação de uma política pública estadual de esportes.

A análise do conteúdo das entrevistas foi realizada por meio da técnica sugerida por Vergara (2005), com a transcrição dos dados logo após sua coleta. A fim de verificar a existência de participação no processo, durante a análise do conteúdo das entrevistas foram utilizadas como referências as formas de participação apresentadas por Enterria e Fernandez (1998) e os instrumentos de participação apresentados por Modesto (2002).

Com base nos dados históricos obtidos nas entrevistas, utilizou-se a terceira técnica de pesquisa: a pesquisa documental. Num primeiro momento, não foram localizadas nas principais bases de dados disponíveis obras acadêmicas a respeito do processo participativo que vem ocorrendo desde 1994 no estado de Santa Catarina para a formulação de uma política pública estadual de esportes. Por isso, num segundo momento, fez-se também uma busca na internet e nos sites das instituições gestoras do sistema, onde foram encontradas informações importantes a respeito do processo, mas que necessitavam de complementação. Entretanto, num terceiro momento foram localizados nas salas arquivo das instituições gestoras do sistema, em especial o CED e a FESPORTE, documentos oficiais, atas, listas de presença, leis vigentes, convites oficiais para a participação em cada fórum, documentos de orientação desenvolvidos para orientar a elaboração da política do esporte, entre outros. Estes documentos contribuíram sobremaneira para a pesquisa, propiciando uma descrição em maiores detalhes do processo participativo que ocorreu para a formulação de uma política pública estadual de esportes em Santa Catarina. Serviram, também, como evidências oficiais da participação de demais atores sociais, além do estado, na elaboração desta política.

\section{DISCUSSÃO DO CASO}

Com base na análise do processo de formulação da política pública do esporte de Santa Catarina, é possível constatar o que Howlett e Ramesh (2003) afirmaram a respeito do modo como o governo pode tratar uma questão específica, considerando opiniões e decisões de outros setores. É dessa forma que o governo possibilita a participação de diversos atores na elaboração de uma política pública.

No caso estudado, há que se considerar a existência da busca pela participação cidadã no processo. Além de ser educativa, servir para desalienação e proteger a liberdade (ROBERTS, 2004), a participação restringe possíveis abusos de um sistema representativo (BARBER, 1984; BOX, 1998; PATEMAN, 1970). 
A forma de participação cidadã neste processo - utilizando-se a classificação das formas de participação na administração pública de Enterria e Fernández (1991) - foi cooperativa. Para os autores, trata-se de uma cooperação prestada de fora da administração, tanto orgânica quanto funcionalmente, porém, que supõe colaborar de uma maneira voluntária em programas ou atividades que a administração promove. A administração, embora possa utilizar de instrumentos coercitivos estabelecendo proibições ou impondo condutas e atuações preceptivas, muitas vezes pode convidar ou até mesmo estimular os atores à participação, respeitando a liberdade de determinação dos indivíduos ou grupos. Com isso, surge a possibilidade para que se aja com liberdade de forma mais conveniente ao interesse geral.

Do ponto de vista desta forma de participação ressaltam-se alguns aspectos da formulação da política pública do estado de Santa Catarina.

A criação do CED em 1993 e, posteriormente, do Sistema Catarinense de Desportos em 1994 permitiu alguns avanços do ponto de vista da participação cidadã. Antes da criação do CED os membros do Conselho de Representantes eram todos indicados pelo governo. Com o advento do CED, os conselheiros passaram a ser indicados pela comunidade por meio dos representantes dos municípios e das regiões do estado e as associações esportivas que estivessem organizadas também passaram a indicar conselheiros para o CED. Verifica-se, assim, que outros atores sociais, além daqueles ligados diretamente ao Estado, passaram a participar de forma mais significativa na definição das questões relativas ao esporte em Santa Catarina. Ou seja, atores sociais de fora da administração pública passaram a colaborar de uma maneira voluntária nas questões esportivas promovidas pelo estado em Santa Catarina. Por sua vez, a administração pública, representada pelo CED, teve a iniciativa de chamar mais atores sociais para participar do processo de elaboração de uma política pública - chamamento que possibilitou uma maior participação no public policy making.

Para que fosse possível a participação cidadã na elaboração da política do esporte catarinense, o principal instrumento utilizado pelo governo foram os colegiados públicos, que, conforme Modesto (2002), resultam de reconhecimento dado a cidadãos, ou a entidades representativas, do direito de integrar órgão de consulta ou de deliberação colegial no poder público. Outro instrumento que também esteve presente no processo foi o da colaboração executiva, que ocorre efetivamente quando organizações desenvolvem, sem intuito lucrativo, com alcance amplo ou comunitário, atividades de colaboração em áreas de atendimento social direto.

A utilização destes instrumentos pode ser observada durante a realização dos Fóruns Catarinenses de Desportos, que ocorreram de 1997 a 2003. Os fóruns foram os principais instrumentos utilizados para propiciar uma maior participação no processo da política pública do esporte.

A convocação para a participação nos fóruns foi realizada, em grande parte, pelos mobilizadores regionais ligados ao CED, que organizavam e mobilizavam as pessoas ligadas ao esporte nos âmbitos municipal e regional do estado. Esta forma de organização trouxe aos fóruns a presença marcante de pessoas ligadas, de alguma forma, ao Sistema Catarinense de Desportos e também às prefeituras municipais do estado. Durante os fóruns, cidadãos e entidades representativas estiveram reunidos, foram consultados, discutiram e deliberaram a respeito do destino do esporte catarinense. Desta forma, os fóruns, em si, foram amplos colegiados públicos de acordo com a classificação de Modesto (2002). Entretanto, além de não haver investimentos ou esforços em comunicação de massa (aberta) para chamar a população a participar destes fóruns, a procura por parte das pessoas, em geral, era baixa. Líderes comunitários e ONG's passaram a estar presentes no processo somente no último fórum, realizado em 2003.

Os colegiados públicos também foram utilizados quando da escolha dos delegados que iriam representar Santa Catarina na I e II Conferência Nacional de Esportes em 2004 e 2006 respectivamente. Reuniões públicas foram feitas nos municípios sede das regiões do estado para nomear os delegados que iriam representar a região na etapa estadual. Durante esta etapa, ocorreu um novo processo de escolha, e apenas 30 dos 300 delegados selecionados inicialmente representaram Santa Catarina na I e II conferência em Brasília. Esse arranjo garantiu que a escolha dos delegados fosse feita com a participação dos atores sociais locais e regionais. O processo foi aberto ao público, os eventos eram gratuitos, o que possibilitava a participação popular. Mediante solicitação, qualquer pessoa poderia participar. Entretanto, uma divulgação mais ampla não foi realizada e, assim como ocorreu nos fóruns, este processo não atingiu amplamente as bases da sociedade, a saber, a parcela da população que tem o interesse, mesmo que latente, de participar das decisões públicas que afetam a sua vida em particular. 
Na análise do caso apresentado, entretanto, é importante entender que o conceito de participação cooperativa é amplo, dentro do qual podem estar diferentes tipos de participação. Pode-se considerar desde o depósito de dinheiro na poupança por parte da população (instigada pela administração pública), até a participação de cidadãos na elaboração de uma política pública. Por isso, tão importante quanto reconhecer a participação cidadã no processo é entender seus impactos no interesse geral da população. Além disso, é de se considerar o que ressalta Britto (1992) ao afirmar que ela (participação) somente ocorrerá quando for possível identificá-la como manifestação de poder político e não como simples expressão de direito público.

\section{CONSIDERAÇÕES FINAIS}

Tendo em vista o objetivo do presente artigo - analisar o processo participativo que vem ocorrendo desde 1994 no estado de Santa Catarina para a formulação da política pública estadual de esportes -, foi possível constatar no caso estudado que houve participação cidadã no processo.

O caso estudado demonstrou um esforço da administração pública para que houvesse a participação dos interessados na discussão, a reflexão sobre o tema e a elaboração do documento da política pública catarinense de esportes. Quanto ao que efetivamente se realizou, podem-se levantar aspectos positivos e negativos, considerando a complexidade inerente à administração pública e à participação cidadã.

Entre os aspectos positivos destacamos alguns a seguir. Com a criação do CED em 1992 e, posteriormente, a consolidação do Sistema Catarinense de Desportos via criação da FESPORTE e do TJD, notou-se uma abertura significativa para os demais atores sociais, além do estado, participarem das discussões sobre o destino do esporte em Santa Catarina. Entre outros aspectos importantes, os conselheiros do CED passaram a ser indicados também pelos representantes dos municípios e das regiões do estado. E as associações que estivessem organizadas também passaram a participar deste processo, podendo, ainda, indicar representantes para compor o CED.

Outro aspecto positivo foi a realização dos fóruns catarinenses entre os anos de 1997 e 2003. Eles representaram um avanço no sentido de possibilitar uma maior participação, uma vez que foram os principais instrumentos utilizados a fim de permitir uma maior participação no processo da elaboração da política pública do esporte.

Além disso, destaca-se também a organização do estado para a participação da I e II Conferência Nacional de Esportes, em Brasília, respectivamente nos anos de 2004 e 2006. A organização e seleção dos delegados que representaram o estado nestes eventos foi feita com a participação de diversos representantes de entidades municipais e regionais ligadas ao esporte.

Entretanto, alguns aspectos negativos também puderam ser observados no processo de formulação da política pública do esporte em Santa Catarina. Entre eles, destacamos a falta de comunicação mais abrangente, no sentido de divulgar os eventos (fóruns e conferências) para um número maior de pessoas interessadas. Ou seja, não houve comunicação de massa para que os atores sociais que não estavam organizados em torno de instituições participassem destes eventos - atores que têm o desejo, ainda que latente, de participar das questões que afetam as suas vidas.

Além disso, a descontinuidade da realização dos fóruns representou um retrocesso no processo participativo que vinha ocorrendo desde 1992. Estes eventos representaram, historicamente, um enorme avanço no sentido de propiciar uma maior participação no processo de formulação da política. Nos fóruns, os participantes se manifestavam de forma organizada e contribuíam com seu conhecimento para o aprimoramento da política pública do esporte em Santa Catarina. Após o fórum de 2003, nenhum outro foi realizado até o ano de 2008. Destaca-se ainda que, apesar de terem sido realizadas duas conferências nacionais, este processo também não tem tido continuidade, tendo em vista que, segundo um dos entrevistados, a III Conferência, marcada para o ano de 2009, foi cancelada.

Entendemos que a complexidade do processo de formulação da política pública do esporte catarinense envolve, entre outros elementos tão ou mais importantes, a peculiaridade da administração pública, dado que neste campo a administração e a política são inseparáveis, uma influenciando a outra e disso resultando os programas e processos participativos. Assim, durante a pesquisa, ficou evidente a influência da política no public policy-making, implicando a participação ou não 
de determinados atores sociais, a inclusão de novos gestores e o rumo da própria política pública. Essa não é uma característica boa ou má, mas que se manifesta por vezes de forma favorável ou não à participação, e implica também relativa efemeridade dos fóruns e conferências.

Como o processo se deu de forma descentralizada, foi fundamental tanto a figura do representante regional do CED como suas estratégias de mobilização popular em torno da elaboração da política pública do esporte em Santa Catarina. Dessa forma, é evidente a importância da postura de quem conduz os processos participativos, de sua competência em fomentar e organizar a participação. Do mesmo modo que a postura dos gestores é crucial, os recursos envolvidos no fomento da participação também o são.

E considerando que o subsistema político é o espaço no qual a política pública opera e inclui tanto os atores sociais que estão profundamente engajados num processo político - as redes de interesse - quanto aqueles apenas perifericamente envolvidos - as comunidades do discurso -, talvez um programa ampliado de incentivo à participação atraísse mais membros da comunidade do discurso (podemos citar como exemplo uma chamada da população utilizando-se a mídia aberta).

Em relação à complexidade da participação, entende-se que a participação cidadã, em seu sentido substantivo, não é algo linear e simples, pois envolve uma série de elementos que não podem ser 'gerenciados', como a cultura, a história e o contexto social e político dos cidadãos. Por isso, considera-se satisfatória a participação neste processo, visto que conseguiu atingir e envolver um contingente considerável de atores da rede de interesse e alguns atores da comunidade do discurso do subsistema da política pública.

Por isso, entende-se que, mesmo não representando a concepção idealizada de participação cidadã, o caso estudado apresenta elementos substanciais que caracterizam a participação de forma cooperativa por meio dos colegiados públicos. Pode-se observar com o estudo realizado que essa participação aumentou de um fórum para outro, o que significa que no desenrolar do processo dos fóruns (de 1997 a 2003) vários elementos confluíram no sentido da participação cidadã. Entre eles, podem-se indicar o aumento do know-how dos gestores na condução do processo e uma expansão da participação de atores presentes na comunidade de discurso, observando-se, no quarto fórum realizado, um aumento considerável da participação de organizações comunitárias e de ONGs no processo.

Esta pesquisa apresenta algumas limitações. Uma delas está ligada à técnica de entrevistas em profundidade, utilizada nesta pesquisa. Tendo em vista que a escolha da amostra não permite atingir um caráter probabilístico, as possibilidades de generalização ficam prejudicadas. E, ainda, as entrevistas em profundidade além de trazerem informações importantes e em profundidade acerca de um fenômeno ou processo, oferecem também os vieses e as ideologias presentes na fala dos entrevistados. Dessa forma, é relevante considerar que podem existir outras opiniões sobre o mesmo processo. Buscou-se superar esta limitação com o auxílio das outras técnicas de pesquisa utilizadas neste estudo.

Intentou-se, aqui, com esta pesquisa, contribuir para o tema participação cidadã, que envolve inúmeros questionamentos e poucas respostas trazidas ao debate. $O$ estudo e análise minuciosa de um caso concreto de processo de formulação de políticas públicas com participação cidadã trazem importantes elementos para provocar a reflexão sobre o tema. Além disso, por meio desta pesquisa foi possível levantar, organizar e documentar um processo que ainda não havia sido investigado a fundo pela academia e que é de extrema relevância para o estado de Santa Catarina. Com isso, esta pesquisa serve de base ou ponto de partida para demais pesquisas que busquem investigar mais a fundo o processo de participação cidadã na elaboração da política pública do esporte catarinense. 


\section{REFERÊNCIAS}

ALBUQUERQUE, M. C. Participação cidadã nas políticas públicas. In: FUNDAÇÃO KONRAD ADENAUER. Participação cidadã: novos conceitos e metodologias. Fortaleza: Expressão Gráfica e Editora, 2004. 15-60 p.

ALVES, J. A. B.; PIERANTI, O. P. O Estado e a formulação de uma política nacional de esporte no Brasil. RAE-eletrônica, v. 6, n. 1, art. 1, jan./jun. 2007. Disponível em: <http://www.scielo.br/pdf/raeel/ v6n1/a02v6n1.pdf>. Acesso em 05/09/2015.

BARBER, B. Strong democracy: participatory politics for a new age. Berkeley and Los Angeles: University of California Press, 1984.

BOBBIO, N. Liberalismo e democracia. São Paulo: Brasiliense, 1988.

BOX, R. C. Citizen governance: leading american communities into the 21st century. Thousand Oaks, CA: Sage, 1998.

BRITTO, C. Distinção entre controle social do poder e participação popular. Revista de Direito Administrativo (RDA), Rio de Janeiro, $n$. 189, p. 114-122, jul./set. 1992.

DENCKER, A. F. M. Métodos e técnicas de pesquisa. 3. ed. São Paulo: Futura, 2000.

DENHARDT, R. B. Teoria Geral de Administração Pública. 4. ed. Tradução de Francisco G. Heidemnann. Arizona: Thomson/Wadsworth, 2004. Digitado.

DENHARDT, R. B.; DENHARDT, J. V. The New Public Service: serving, not steering. New York: M.E. Sharp, 2003.

DYE, T. Understanding public policy. 10. ed. New Jersey: Prentice Hall, 2002.

ENTERRIA, E. G.; FERNÁNDEZ, T. R. Curso de direito administrativo. Trad. Arnaldo Setti. São Paulo: Editora Revista dos Tribunais, 1991.

ENTERRIA, E. G; FERNÁNDEZ, T. R. Curso de Derecho Administrativo. 5. ed. Madrid: Ed. Civitas, 1998. v. II.

FILIPPIM, E. S.; ABRUCIO, F. L. Quando descentralizar é concentrar poder: o papel do governo estadual na experiência catarinense. RAC, Curitiba, v. 14, n. 2, p. 212-228, mar./abr. 2010.

GIL, A. C. Métodos e técnicas de pesquisa social. São Paulo: Atlas, 1999.

HABERMAS, J. O papel da sociedade civil e da esfera pública política. In: HABERMAS, J. Direito e democracia. Entre a facticidade e a validade. Tradução de Flávio Beno Siebeneichler. Rio de Janeiro: Editora Tempo Brasileiro, 2003. 57-121 p.

HOWLETT, M.; RAMESH, M. Studying public policy: policy cycles and policy Subsystems. Tradução de Francisco G. Heidemnann. Toronto: Oxford University Press, 2003. Digitado.

KISSLER, L.; HEIDEMANN, F. G. Governança pública: novo modelo regulatório para as relações entre Estado, mercado e sociedade? Rev. Adm. Pública, v. 40, n. 3, p. 479-499, maio/jun. 2006.
MCCARTHY, Thomas. La Teoria Critica de Jurgen Habermas. Madrid: Ed. Tecnos, 2013.

MODESTO, P. Participação popular na administração pública. Mecanismos de operacionalização. Jus Navigandi, Teresina, v. 6, n. 54, fev. 2002. Disponível em: <http://www1.jus.com.br/doutrina/ texto.asp?id=2586>. Acesso em: 10 jul. 2009.

NEF, J. Administração Pública e Reforma do Setor Público na América Latina. In: PETERS, G.B.; Pierre, J. (Orgs.). Administração Pública. São Paulo: Ed UNESP, 2010. Coletânea.

PATEMAN, C. Participation and democratic theory. Cambridge, MA: Cambridge University Press, 1970.

ROBERTS, N. Public deliberation in an age of direct citizen participation. American Review of Public Administration, v. 34, n. 4, p. 315-353, 2004.

SALOOJEE. A.; FRASER-MOLEKETI, G. Desafios comuns a reformas administrativas em países em desenvolvimento. In: PETERS, B. Guy; PIERRE, Jon. (Org.). Administração Pública. São Paulo: Ed. UNesp, 2010. Coletânea.

SOUSA SANTOS, B. A reinvenção solidária e participativa do Estado. In: A gramática do tempo: para uma nova cultura política. Editora Cortez. São Paulo, 2006. 341-376 p.

SOUSA SANTOS, B.; AVRITZER, L. "Para ampliar o cânone democrático". In: SANTOS, B. de S. (Org.). Democratizar a democracia: os caminhos da democracia participativa. Rio de Janeiro: Civilização brasileira, 2003. 43-82 p.

SUASSUNA, D. M. F. Políticas públicas para o esporte e o lazer no Brasil (1996-2005). In: SUASSUNA, D.; AZEVEDO, A. (Org.). Política e Lazer: interfaces e perspectivas. Brasília: Thesaurus, 2007. 240 p.

TEIXEIRA, E. C. As dimensões da participação cidadã. Caderno CRH, Salvador, n. 26/27, p. 179-209, jan./dez. 1997.

TENORIO, F. G.; SARAVIA, E. J. Escorços sobre gestão pública e gestão social. In: MATOS MARTINS, P. E.; PIERANTI, O. P. (Org.). Estado e Gestão Pública. Visões do Brasil Contemporâneo. Rio de Janeiro: Ed. FGV, 2006.

UNESPORTE. Documento de orientação para a política do esporte catarinense. Florianópolis, SC, 2009. Impresso.

VAZ, A. F. Políticas públicas para o esporte e o lazer em Santa Catarina: reflexões e considerações. Revista da Educação Física/UEM, Maringá, v. 12, n. 1, p. 89-96, 1. sem. 2001.

VIEIRA, M. M. F. Por uma boa pesquisa qualitativa. In: VIEIRA, M. M. F.; ZOUAIN, D. M. (Org.). Pesquisa qualitativa em administração. Rio de Janeiro: Ed. FGV, 2004.

YIN, R. K. Estudo de caso: planejamento e métodos. 2. ed. Porto Alegre: Bookman, 2001. 
Clerilei Aparecida Bier

Doutora em Direito pela Universidad Complutense de Madrid; Pós-doutora pela Faculty of Business- University of Technology, Sydney/Austrália; Pós-doutora pela Universitat de Barcelona; Professora da Universidade do Estado de Santa Catarina/Centro de Ciências da Administração e SócioEconômicas-ESAG. E-mail: clerilei.bier@udesc.br

\section{João Paulo Bittencourt}

Doutorando em Administração pela Universidade de São Paulo (USP); Membro do grupo de pesquisa em Gestão Estratégica de Pessoas; Mestre em Administração pela Universidade Estadual de Santa Catarina.Email: bittencourtjp@usp.br

\section{Cauê Martins Franco}

Bacharel em Ciências Sociais pela Universidade do Estado de Santa Catarina; Coordenador de Socioeconomia na Terracal Alimentos e Bioenergia. Email: caue22@hotmail.com

\section{Clarissa Iser}

Mestre em Administração pela UDESC/ESAG, na linha de Políticas Públicas e Terceiro Setor; Graduada em Administração (UDESC/ESAG) e Turismo e Hotelaria (UNIVALI); Diretora da PROJETA Planejamento e Marketing. Email: clarissa@projetaonline.com.br

Cad. EBAPE.BR, v. 14, nº 3, Artigo 6, Rio de Janeiro, Jul./Set. 2016. 